\title{
Science as a Human Endeavour: Outlining Scientific Literacy and Rethinking Why We Teach Science
}

\author{
Alison J. Sammel \\ Education and Professional Studies, Griffith University, Gold Coast, Australia \\ Email: a.sammel@griffith.edu.au \\ Received 21 April 2014; revised 25 May 2014; accepted 10 June 2014 \\ Copyright (C) 2014 by author and Scientific Research Publishing Inc. \\ This work is licensed under the Creative Commons Attribution International License (CC BY). \\ http://creativecommons.org/licenses/by/4.0/

(c) (i) Open Access

\begin{abstract}
What does it mean to be scientifically literate? Historically, dominant understandings of scientific literacy focus on science content acquisition. However, new understandings imply more genuine and authentic interactivity between science content knowledge/skills and understanding of the economic, sociocultural, religious, ecological, ideological, political and temporal connections upon which the science is based: this is the task of Science as a Human Endeavour. This paper presents a snapshot of what Science as a Human Endeavour is, its purpose and factors to consider. Science as a Human Endeavour doesn't just necessitate that we change our teaching practices: it forces us to rethink the teaching and learning of science and the reason why we are doing it.
\end{abstract}

\section{Keywords}

Science Education, Science as a Human Endeavour, Nature of Science, Scientific Literacy, Emancipatory Education

\section{Introduction}

It is widely agreed that the term "scientific literacy” is a slogan within science education "meaning all things to all people”, however it is also agreed that it does "serve to indicate the intentions of science education” (Holbrook \& Rannikmae, 2009: p. 277). Teaching approaches based around enhancing scientific literacy are therefore not only viewed as a good thing, but a goal for science education. While the term has come to have nuanced meanings, Holbrook \& Rannikmae (2009) suggest there is a movement away from scientific literacy "being viewed as the possession of conceptual understanding of pure science abstract ideas" towards the "ability to make decisions related to the technological applications of scientific ideas or socioscientific issues facing socie- 
ty” (p. 279). This trend has evolved from a number of critiques questioning the emphasis on conceptual understanding. The major critiques include:

- The foregrounding of conceptual knowledge and conventional scientific processes at the expense of skills such as reasoning, communication and exploring more socially and, I would add, environmentally, responsible science (AAAS, 1989; Eisenhart, Finkel, \& Marion, 1996; Reveles, Cordova, \& Kelly, 2004).

- If conceptual knowledge is key, then who decides what type of knowledge the general public should have in relation to the vast breath of scientific knowledge (Apple, 1999; Hodson, 1999; Reveles, Cordova, \& Kelly, 2004).

- Being scientific literate needs to be situated within a collective experience, rather than being thought of as an individual attribute. A student who is simply a "receptor" of science facts and is able to read, write and talk science is not necessarily scientific literate, as he must also understand the fundamental conceptual, epistemic and social dimensions associated with the scientific community; he must appreciate the collective view of what it means to do science, of how to think, communicate and argue in the beliefs and language of science (Lemke, 1990; Roth \& Lee, 2002).

This updated understanding of scientific literacy implies more genuine and authentic interactivity with the knowledge base within which science is situated. It highlights that school science is more than just improving student's science concept knowledge and skills, as it seeks to review science itself while also placing the science. The students are exploring within the economic, sociocultural, religious, ecological, ideological, political and temporal environment of their local, national and international communities. This goal encourages student to have mastery of science concepts, and be able to make well thought through choices based on well-researched information, and develop skills that promote engaged citizenship within their democratic societies. To achieve this, teachers need to help students become responsible citizens able to think critically and creatively, analyse information, and more accurately appraise the associations and impacts of the countless choices and actions they make.

This is the key task of an aspect of science education called Science as a Human Endeavour. This article will present a snapshot of what Science as a Human Endeavour is, its purpose, factor to consider and finally what it can look like in practice.

\section{What Is Science as a Human Endeavour? And What Is Its Purpose?}

Science as a Human Endeavour should not be defined by a single description but rather viewed as a movement in science education that is connected by the principle that science education is equally about people and culture as it is about science content and skills. This movement is not fixed, but continually changes and grows. As science does not exist outside the context of society, the foundations that underpin this movement emphasizes personal relationships to science within wider contexts and histories, and promotes active and transformative learning. Specifically, it promotes a teaching and learning of science that is reflective of science, places knowledge within sociocultural frames and contributes to developing better decision-makers. It aims to contribute to student's abilities to be critical and creative thinkers, establish ethical principals, building language and negotiation skills, and lead to a greater sense of ownership and pride in being a lifelong learner. It responds to the call for science to be grounded in the lived experiences of the students while also connecting to the sociocultural environment of the community. This lived experience shapes students thinking and understanding of science and motivates learning in lasting and personal ways.

As Science as a Human Endeavour speaks to the interactive aspects of how science and society relate and influence daily lives, it doesn't just necessitate that we change our teaching practices: it's forcing us to rethink the teaching and learning of science and the reason why we are doing it. It involves viewing science education differently; and ensures that educators bring a variety of perspectives into their teaching and learning of science. And making this transition will mean envisioning science's deep connection to people and culture. It means understanding that teaching science implies that science itself needs to be reflected on, and even critiqued. It means placing the discipline of science within socio-cultural frames and allowing the students to view the current and historical nature of science. In this sense, effective science education to promote scientific literacy necessitates the interactivity of 3 agendas: students generating a conceptually accurate understanding of the science concept being taught (via constructivist methods); students developing the ability to reflect on the nature of that science (Nature of Science: the philosophies, agenda, history and practices of science itself); and thirdly, for students to place all of this information within a wider socio-cultural framing (Science as a Human Endeavour). 


\section{Considerations in Science as a Human Endeavour}

Exploring the relationships between science and sociocultural knowledge associated with the chosen topic involves considering the consequences and implications of issues. Allowing students to fully explore how each piece of information, and their implications are interconnected through multiple systems will help students come to an appreciation of the anatomy of the topic. Depending on the final teaching goal, the nature of the exercise might not be to seek solutions to problems, but to start to see the multiple perspectives and agendas, and understand the "hows and whys" of the issues. This may involve [helping] students conceptualize different and better questions than what they might originally pose. If the agenda is awareness raising, then the complexity of thought and involvement should increase as learners progress through school, just as their knowledge should increase in quality and depth. However, if the goal of teaching Science as a Human Endeavour is to emancipate students to seek solutions, whether they are hypothetical, or ideally solutions that can be actualized, then further steps are needed. The same explorations as above would take place, but students would need to make decisions about issues, and articulate what solutions they believe would be most appropriate. Then they can work towards those solutions. This is a skill that needs to be taught. An important process in working towards forming solutions implies understanding systemic constrains, as well as your own. These may include, time, resources, desire and ability. Student may design revolutionary plans, but need to understand that it is most likely small scale change that make sustainable differences: evolution rather than revolution. Students should also be encouraged to form educated arguments for where the dividing line is between acceptable and unacceptable forms of social action.

If considering the emancipatory approach, Hungerford \& Volk (1990) suggest categories of actions that students could consider. An updated adaptation of their original work suggests students:

- Taking direct physical action to improve the situation, using less electricity, walking to school, thinking about things more thoroughly before you saying or act.

- Taking persuasive action, trying to convince people or groups that certain actions are more appropriate ways of thinking or undertaking things (letters to the editor, awareness campaigns, public discussions).

- Taking consumer action, researching the policies, agendas and practices of companies and choosing to support or boycott them via buying or not buying their products.

- Political action, putting pressure on government representative or agencies to persuade them to take a certain action (this may include inviting local representatives in to the school to hear the students' educated concerns and solutions... it may also involve having their voting parents/guardians present).

- Legal action, this action uses the legal system to bring about changes to issues.

No matter what the style, any actions should be student generated and led. When the solutions are teacher suggested and focused, they are less likely to be authentically acted on by the students. Further, it is essential for teachers to help students believe in their effectiveness to generate change. Research has show that students who have a greater internal locus of control believe that it is within their ability to make an impact on issues (see Sammel, 2012), and are therefore more likely to desire to work towards solutions. A student who has a high external locus of control believes they cannot control what is happening around them and is more likely not to try. Providing students with the opportunity to learn the skills of Science as a Human Endeavour in small steps will help students see they can explore issues and can achieve success in obtaining results, whether it be in their own lives, in the lives of their families, school or the wider community. This is reflective of learning anything new.

Before students can articulate their decisions around explored topics, it is important for them to know the difference between an "issue" and a "problem”. Hungerford \& Volk (1990) explain the difference between the two as being that a "problem" is a threat or difficulty associated with the topic, whereas an "issue" is when individuals or groups disagree about the nuances of the problem or disagree around what should be done in relation to addressing the problem. This understanding maintains that differing beliefs, agendas and values underlie issues. This is why issues are so complex, as each individual and group may have many beliefs and values associated with the problem. An understanding of various perspectives, along with personal refection is essential. Students should reflect on how their values, beliefs and actions are intertwined with the chosen issue. The students might come to understand that their own thoughts and behaviours are developed from the communities they are associated with.

When the educational community comes together to begin the process of designing implementation strategies planning needs to look at pedagogies associated with scaffolding the science concepts, to ensure mastery of 
content; the generation of reflection on the Nature of Science associated with that science; and how the science content can be framed with sociocultural agendas. The following considerations are offered to bring insight to the process of implementation. This guideline borrows Hickman, Patrick \& Bybee (1987) questions for decision makers, and Hungerford \& Volk's (1990) strategies for teaching in the fields of Science, Technology and Society, and related movements. Questions and strategies that planners, developers and teachers could reflect on as they develop curricula are:

Questions:

- Does the material reflect teaching socially and environmentally significant issues, science concepts, and the Nature of Science and encourage the students explore the interrelationship that exist within and between these concepts?

- What overt and covert goals are going to be promoted in this material?

- Is the topic an important issue in society today and will it continue to be so? Should students be informed about this issue in the future, as it will have implications for them and their society?

- Is the material chosen directly relevant and applicable to the lives of the students? Is it a topic that students can be interested in? Does it related to their hobbies and lifestyles?

- Can the students see the applicability of this knowledge in other contexts? Can they see how the skills (researching, analysing, argumentation etc.) and the content (the topic) can be applied to other parts of their lives?

- Do constructivist teaching and learning styles form the basis of this learning? This implies that learning is viewed as the active construction of knowledge. This should be achieved by scaffolding and gradually expanding networks of ideas by working with both peers and mentors, and utilising the materials within the environment.

- Will the materials teach the skills of investigation and analysis, critical and creative thinking and decisionmaking, and effective communications (such as active listening and the ability to support your arguments in respectful ways)?

- Does the material provide a curriculum that results in an in-depth knowledge, the exploration of their implications, and a fair presentation of a variety of perspectives, while also teaching the associated science?

- Does the material provide carefully designed and in-depth opportunities for students to achieve some level of understanding about these interconnections that will promote a sensitivity or desire to generate action (in their own lives or in the community)?

- Is the material matched to the cognitive developmental level of the students? Can questions of the underlying issue be modified to meet the age level of the student? For example, if the topic involves the patenting of drugs and its implications, can this issue be first explored in the context of sharing what is "owned" within the student's own house and the implications?

- Is the classroom teacher directly involved with short and long term planning and development of the curricular? Teachers must build on their own interests and reflect on their beliefs about the role and nature of science education before they can begin to cognitively engage with curricula development.

- Does the material promote opportunities for students to be involved in the planning of the unfolding learning experience? Can students have direct experiences with helping create solutions? Does the teacher work cooperatively with the students to hear and act on suggestions based on their interests and the issues confronting them? Can students form their own questions based on the central topic?

- Does it creatively evaluate and assess in ways that complement what the students are doing and learning?

- Does it promote learning materials that portray feelings and emotions associated with perspectives, rather than just neutralized facts?

- Does the material promote collegial and accepting relationships?

- Does the classroom curriculum have harmony between the message and the medium? If the "messages" explored in the classroom center on the foundations of equity, fairness, justice, compassion etc., is this reflected in the workings of the classroom? This may look like the promotion of dialogue, valuing the contributions of all students to the learning environment, co-learning and decision-making, negotiations and a general movement towards the de-centralisation of power where able. How might this be reflected on and improved, from the teacher's and students' perspective?

- Does the material allow students to learn about applicable general rules, codes and laws in their simplest terms? 
- Does the material provide the time for students to experiment and apply the above skills?

To be successful at Science as a Human Endeavour, the teacher must employ the virtues of being accepting, fair, just, genuine and empathetic. The teacher should accept the student's personality (but this does not mean approving of inappropriate behaviour) and should trust the students with letting them hear the teacher's own arguments around perspectives when it is appropriate to do so. However, most importantly, the teacher should always model what it is like to be "the other person" and seek to understand the feelings and meanings behind what a student does or does not say. It requires the teacher to be able to vision across all kinds of overt and covert boundaries.

\section{Approaches to Science as a Human Endeavour}

Designing effective units can be a complicated and difficult task, even when the goals are simple and clear-cut. With Science as a Human Endeavour it can be even more so, as we must begin by deciding what we want this education to achieve and what end point we are moving towards, before we proceed to planning.

After the topic has been chosen based on the curriculum, the next step may be to determine how each of the three interactive agendas of effective science education to promote scientific literacy can be developed. What is the best pedagogical approach to teach the science content, the Nature of Science, and the economic, sociocultural, religious, ecological, ideological, political and temporal issues associated with that topic? Beginning this may involve researching issues associated with the topic, finding something that grabs interest for the teacher and students. In finding this focus, an evaluation of what information to include and what to omit needed. The "science" content side would involve achieving a detailed understanding of science the underlying the topic, the associated alternative conceptions, and what pedagogical approaches would best scaffold the learning (see considerations above). The Nature of Science side may consist of understanding how the knowledge of the topic was generated, and exploring the assumptions, implications and issues underpinning its history, present and future. Questions like: how and why did the scientist come to generate this understanding? What kinds of experiments were done, and any [ethical] implications to these? Were there alterative theories? Why were they abandoned? What might have underpinned their thinking? How did their thinking relate to that temporal era? Finally the sociocultural side may involve understanding the key issue that relates to the topic and building a conceptual map of the factors and groups associated with this issue.

Pedagogically, this may involve building spaces for students to engage in a variety research avenues (books, journals, internet, people, groups, government resources etc.). This could include generating research questions; developing ways to seek answers to these questions; reflecting on personal ideas, assumptions and beliefs; researching dominant ideas around the issues and understanding these perspectives and their consequences; finding alternative perspectives, solutions and exploring their consequences; comparing information and analysing bias and being able to come to a well informed decision and being able to articulate and defend that position. This will necessitate a high degree of active cognitive involvement, the use of cooperative learning strategies, and the inclusion of assessment items that activate a higher level of cognitive processes. The main pedagogical imperative is for the learner to construct his or her own understanding. Providing stimulating and motivational experiences that challenge students' existing conceptions and involve them actively in the teaching/learning process can facilitate this.

Pedretti \& Nazir, (2011) developed a conceptual mapping of how, in science education, teachers usually link science content to sociocultural issues. They suggest there are six ways or "currents" that are used in classrooms to achieve this end. These currents are: Application/Design; Historical; Logical Reasoning; Values Centered; Sociocultural; and Socio-Ecojustice. By generating a deeper understanding of these 6 currents, and their associated advantages and disadvantages, educational developers/teachers can more effectively reflecting on their own assumptions of Science as a Human Endeavour, and generate needed changes.

In discussing each of these 6 currents I will compare different approaches in teaching about "bees". These examples are founded on the principles of Science as a Human Endeavour. Students in the younger years might be asked to investigate bees. They might find out all of the relevant, accurate science information behind bees (anatomy, behaviors, the role they play in the ecosystem etc.), while also exploring how scientists and others have developed this knowledge through ways of working with bees. They might also investigate the history of bee populations in their local areas and research, discuss and debate all the various factors and implications of why there might be changes to these populations. They might be asked to develop solutions to problems they 
consider important that have become evident due to their research.

\subsection{Application/Design}

The goal and pedagogical strategies associated with this current involves the use of problem solving through technology. This may involve "designing new technology or modifying existing technology with an emphasis on inquiry and skills” (Pedretti \& Nazir, 2011: p. 606). Teaching strategies can incorporate problem-based learning, designing and building artifacts. In this current, when exploring the concept of "bees", students could be asked to show their mastery of their knowledge of bees through the use of technology. This could be something like designing a new species of bee, thus highlighting the student's knowledge of the bee and its "vulnerabilities" within a certain ecosystem. This creative expression can be fun and stimulating for the learner, but it may not go beyond conceptual understandings. Students may not appreciate the Nature of Science aspects or sociocultural interconnections illustrated in the example above.

Pedretti \& Nazir, (2011) outline further criticisms associated with this current and suggest that rarely is the complexity surrounding technological design addressed with students. Deepening the Science as a Human Endeavour focus might include asking students to consider the economic and aesthetic factors driving design within society. In some units this may include considering the social and environmental impacts of the cradle to grave use of materials. Another criticism with this current is that without adequate opportunities to deeply consider a wider social context (i.e., the political and economic factors that drive technological design, or the negative impacts of technology) students may think that technology, regardless of it importance for society, can, will and must solve all of societies' problems. Students need to come to understand for themselves that technological developments are only one part to a larger puzzle.

\subsection{Historical}

In this current, students are asked to understand scientific ideas and scientists' work within historical and sociocultural frames. Teaching strategies may include historical case studies, role-play, and drama simulations. In relation to the teaching of bees, students may be asked to find out what role scientists have played, and are currently playing, in relation to topics associated with bees. The students might follow the history of a concept relating to bees within the scientific community. They might follow one specific scientist and discover what she or he has learned from working with bee and bee products and their implications for society. This current humanizes science by highlighting the lives of scientists and shows them as people who are enmeshed within their culture. By focusing on, and extending students' understanding of historical and sociocultural aspects of scientific ideas and the work of scientists, insightful conversations may occur. A common criticism with this current "is that in practice classroom activities tend to highlight stories of success or 'hero stories' rather than stories of the failures of science” (Pedretti \& Nazir, 2011: p. 611). These histories may be based on questionable accounts and may reinforce stereotypes and myths about science and scientists. An alternative may be to organize an indepth examination of critical incidents from the scientists' life, such as how they came to "discover” the science they are accredited with. These dramatic recreation or simulation should also explore what was happening in the wider society at that time and how this impacted the development of science. As such, it is not enough to just introduce scientists but there is an important need to place their work and knowledge within the sociocultural context of that era.

\subsection{Logical Reasoning}

Understanding socioscientific issues and employing decision-making skills through the careful consideration of empirical evidence is the goal for this current. Teaching strategies may include the use of socioscientific issues to explore risk/benefit analysis, stakeholder analysis, the use of argumentation and case studies. This current has been a common way to structure socioscientific investigations, as it is a natural extension to scientific thinking. Here the underlying tenant is that a comprehensive understanding of the science behind an issue, along with the effectively practicing of the rules of logic, would lead to students making better decisions. The students ultimately are practicing thinking like a scientist. In the bee example, students (at an older level) may be given the issue of urban deforestation and habitat loss, and have to use the scientific evidence to make a decision about the use of a piece of land in the city (should it be left in a semi-natural state, sold to developers, or reimagined some 
other way?). Researchers in the field of science education have provided examples of linear steps students can undertake to move towards this kind of critique and decision-making process. Criticism of this current highlight that it assumes that a rational, scientific understanding of "the" issue will lead to positive decision making. As (Pedretti \& Nazir, 2011) reflect, many researchers are questioning the philosophy that equates logical thinking with rationality and wisdom, and reflect on how this way of knowing is privileged in society (e.g., Gilligan, 1977; Noddings, 2002). The absence of consideration into "non-logical factors" such as feelings, desires, beliefs, values, spirituality, cultural norms, economics and politics in these logical decisions needs to be reflected on. The logical reasoning approach may act to strengthening students' skills of argumentation, but in the process may consciously or unconscious promote notion that issues abide outside the realm of these non-logical considerations. Just as people do not have the privilege of operating apart from these non-logical considerations, so too must science education highlight that non-logical considerations do factor into decision-making. These nonlogical considerations must be included in issues-based science education.

Using only scientific information to encourage someone to stop smoking is a poignant example that logic alone is not sufficient to change people's decisions. Showing someone the science, statistics and consequences of smoking will not necessarily lead to them to stop smoking. Each individual will make decisions in their lives based on various factors, and even thought science education needs to teach the processes of science, it must be appreciated that a deeper knowledge of these processes will not necessarily mean that even when applied, people will make better decisions every time. Logical, rational, reasoning skills are part of the scientific process, but it may be a non-logical factor that sways any decision. Pedretti \& Nazir, (2011) state that science education literature is noticeably silent about how non-logical factors come into the teaching and learning of science. Therefore, for students to really understand the issues they are debating, a broader sociocultural framing is needed.

\subsection{Values Centered}

This current promotes understanding issues and decision making about socioscientific issues through consideration of ethics and moral reasoning. Teaching strategies may include analysing socioscientific issue(s), the use of moral frameworks, asking students to clarify their values and make moral decisions. This is a common approach to the teaching of Science, Technology and Society and Science, Technology, Society and the Environment. It seeks to illustrate how science is value-laden enterprise. The student focuses on ethics and moral reasoning when exploring science's interactions with sociocultural issues. The aim is to promote citizenship and civic responsibility. In the example of the bees, students might be asked to investigate bee industry practices, the assumptions, values and treatments afforded to bees and science's role in creating and supporting these agendas and practices. Alternatives might be explored and discussed. Depending on how a unit is planned, sociocultural assumptions can be deeply explored. It may be argued that the scaffolding of science content may be less of a focus in this current. A teacher might seek to engage the moral, emotional and cognitive identities of students. An ongoing criticism of this current is that there are no universal values, and as such, there may be little classroom agreement of value positions. However, depending on the teaching agenda, this current is a great way to increase awareness and can lead to students making individual decisions and generating actions.

\subsection{Sociocultural}

This current focuses on creating the link between science and technology and the broader sociocultural context. Teaching strategies may include case studies, the use of socioscientific issues, storytelling and the inclusion of alternative knowledge systems e.g., traditional and spiritual. Many of the same bee suggestions as above could be employed here. The down side of this approach emerges when students get caught up in multifaceted social issues, where too many layers of complexity are generated, and rather than helping students to see a bigger picture, these abstraction can muddy their understandings. With teaching via this current, it needs to be understood that within any unit, students will never have a "complete" picture of the issues, but if a balance of perspectives and agendas are structured into the learning framework, then students may develop greater awareness so can make better decisions.

Further, the educational community developing these units needs to ensure they do not privilege Western, middle-class viewpoints, and must ensure "alternative" perspectives are included. These may include Indigenous and other cultural perspectives. Discussions about how other cultures understand, value and consider bees, and the roles they, and their products, play in cultures can be investigated and discussed. This may involve discus- 
sions of how students' understand what knowledge base is considered "accurate" or "correct", and may also involve a deconstruction of power afforded to different perspectives within society.

\subsection{Socio-Ecojustice}

This last current focuses on generating exploration, awareness and the critique of the social and ecological problems caused by human agency or action. The aim is to generate student emancipation and action. Teaching strategies may include the use of socioscientific issues, case studies, community projects, debates, developing action plans, within local and global contexts. Pedagogical approaches emphasize critical and creative, affective, reflexive, experiential, and place based learning styles. There are many different ways of enacting this current but they all promote citizenship and civic responsibility via enhancing the students' sense of justice around sociocultural, and environmental issues.

Linking this back to the bee example, students could be asked to investigate what products (they use) have bee compounds in them. They could find out how the bees were "farmed" and the products processed. They might also compare similar products that include and do not include bee compounds and compare each in relation to the positive and negative impacts on the sociocultural (economic, manufacturing process, etc.) and ecological environments. They may then be asked to make democratic choices and create actions, i.e. this may include developing action plans, changing their own habits (boycotting certain products and buying others), educating others (raise awareness about native bees - what they look like and what roles they play in the students' lives), lobbying for change (writing letter to the companies, supporting online petitions), raising funds, and engaging in activities directly with the natural environment (buying a hive of native bees and/or planting trees to attract the bees). These activities engage students cognitively and creatively and have been shown to be inclusive of students normally marginalized by science education.

A concern with implementing this current is that teachers may feel uncomfortable with teaching towards democratic actions and feel that the perspectives involved may be counter hegemonic (going against the grain of society's dominant agendas and perspectives). Pedretti \& Nazir, (2011) suggest that questions arise between which perspectives and agendas should be included.

\section{Conclusion}

This article has shown that scientific literacy implies more than just an understanding of science content knowledge and the ability of students to engage in the scientific process. It has highlighted that for students to meaningfully engage in science they must link it to their own lives and communities. The teaching of this requires providing the opportunity for students to explore the interactions between science pedagogy and content knowledge, the Nature of Science, and associated economic, sociocultural, religious, ecological, ideological, political and temporal environment contexts (Science as a Human Endeavour). Science as a Human Endeavour should not be seen as the pinnacle. It is one of many approaches to deepen student's engagement with science, however with the new initiatives of the Australian Curriculum (Science), this philosophy is mandatory for classroom inclusion. As such, if ever there was a prescription for fundamental change in science education, this is it. While the tradition ways of understanding science education will undoubtedly survive, incorporating Science as a $\mathrm{Hu}-$ man Endeavour will involve not only understanding the philosophies and principles fully, but also appreciating the benefits and limitations to how curricula can be altered and the different approaches to unit design. This may be a tall order, but ignoring its implementation is not an option. Everything changes: the science education of tomorrow will hopefully be different from the science education of today. The center of gravity for science teaching has shifted, and the goal now might be to develop individuals who think for themselves and can move towards making more informed decisions and actions.

\section{References}

American Association for the Advancement of Science (AAAS) (1989). Science for all Americans: Project 2061. Washington DC: AAAS.

Apple, M. W. (1999). Power, Meaning, and Identity: Essays in Critical Educational Studies. New York: P. Lang.

Eisenhart, M., Finkel, E., \& Marion, S. F. (1996). Creating the Conditions for Scientific Literacy: Are-Examination. American Educational Research Journal, 33, 261-295. http://dx.doi.org/10.3102/00028312033002261 
Gilligan, C. (1977). In a Different Voice: Women’s Conceptions of Self and Morality. Harvard Educational Review, 47, 481-517.

Hickman, F. M., Patrick, J. J., \& Bybee, R. W. (1987). Science/Technology/Society: A Framework for Curriculum Reform in Secondary Schools Science and Social Studies. Boulder, CO: Social Science Education Consortium, Inc.

Hodson, D. (1999). Going beyond Cultural Pluralism: Science Education for Sociopolitical Action. Science Education, 83, 775-796. http://dx.doi.org/10.1002/(SICI)1098-237X(199911)83:6<775::AID-SCE8>3.0.CO;2-8

Holbrook, J., \& Rannikmae, M. (2009). The Meaning of Scientific Literacy. International Journal of Environmental and Science Education, 4, 275-288.

Hungerford, H. R., \& Volk, T. L. (1990). Changing Learner Behavior through Environmental Education. Journal of Environmental Education, 21, 8-22. http://dx.doi.org/10.1080/00958964.1990.10753743

Lemke, J. L. (1990). Talking Science: Language, Learning and Values. Norwood, NJ: Ablex.

Noddings, N. (2002). Educating Moral People: A Caring Alternative to Character Education. New York: Teachers College Press.

Pedretti, E., \& Nazir, J. (2011). Currents in STSE Education: Mapping a Complex Field, 40 Years on. Science Education, 95, 601-626. http://dx.doi.org/10.1002/sce.20435

Reveles, Cordova, \& Kelly (2004). Science Literacy and Academic Identity Formulation. Journal of Research in Science Teaching, 41, 1111-1144. http://dx.doi.org/10.1002/tea.20041

Roth \& Lee (2002). Scientific Literacy as Collective Praxis. Public Understanding of Science, 11, 33-56. http://dx.doi.org/10.1088/0963-6625/11/1/302

Sammel, A. (2012). Science Teacher Identity and Justice Education. LAP LAMBERT Academic Publishing. 